\title{
Design controler of the quasi-time optimization approach for stabilizing and trajectory tracking of inverted pendulum
}

\author{
Nguyen Xuan Chiem ${ }^{1, *}$, and Hai Nguyen Phan ${ }^{2}$ \\ ${ }^{1}$ Automation \& Engineering Department, Le Quy Don Technical University, Hanoi, Vietnam \\ ${ }^{2}$ Department of Software Engineering, Le Quy Don Technical University, Hanoi, Vietnam
}

\begin{abstract}
This article describes the method of stabilizing and tracking the trajectory of the inverted pendulum with the quasi-time optimization approach. The controller proposed in this paper is not only to stabilize the inverted pendulum in a vertical position but also to cause the inverted pendulum to follow a predetermined reference signal even when there is an interference effect. The focus of this project is the design of a quasi-time control law based on the quasi-time optimization approach and Lyapunov stability theory. The simulation and experimental results suggest that the proposed controller controls the inverted pendulum balance and cart position stability which are better than the LQR method even when there is an external disturbance effect.
\end{abstract}

\section{Introduction}

The inverted pendulum attached to the vehicle is a typical case study. It is an unstable nonlinear system that is often used to test the performance and effectiveness of control algorithms [1-4]. Many algorithms have been successfully applied to two - free - step inverted pendulum systems, such as the PID for the one - step - inverted pendulum[1,15], the controller based on fuzzy logic $[13,16,18]$, used the noron network[8,27], used the controller that has the sliding mode[2,5,7,12,17], optimal control LQR $[5,6]$. In which LQR is a typical balance controller that gives good simulation results as well as experimental results[2,7,12]. However, determination the value of the matrix $\mathrm{Q}$ and $\mathrm{R}$ at the experimental time for getting stability of the system takes a lot of time.

The fast approach of the quasi-time optimization approach (KOB) for combining control rules is designed by professor Neidorf R.A and developed by his students [22-25] shows that this is a powerful design method and flexible for nonlinear systems [11,26]. This method has been applied to some nonlinear systems and gives good results.

In this paper, authors also uses the fast approach of the quasi-time optimization approach and the Lyapunov stability theory to determine the control rule and parameters of the response speed. This control rule is implemented on real - time embedded systems. We also have compared the control quality with the LQR controller on the same model.

\footnotetext{
${ }^{*}$ Corresponding author: nguyenxuanchiem83@gmail.com
} 


\section{Mathematical model of the Single Inverted Pendulum}

The inverted pendulum model consists of a vehicle and a pendulum attached to that vehicle (Fig. 1), the position of the vehicle is able to be controlled. Suppose that friction and moment of inertia are ignored. The nonlinear model of the pendulum system is constructed using the Euler-Lagrange equation.

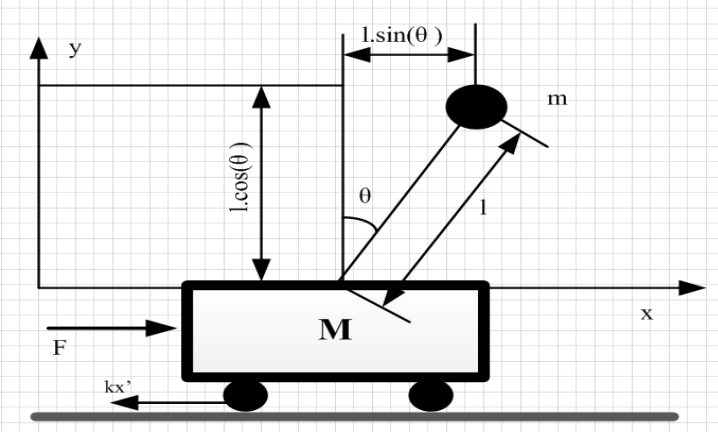

Fig. 1. The inverted pendulum model.

Kinetic energy of the pendulum mass:

$$
T_{p}=\frac{1}{2} m \dot{x}^{2}+m l \dot{x} \dot{\theta} \cos (\theta)+\frac{1}{2} m l^{2} \dot{\theta}^{2}
$$

Kinetic energy of the vehicle:

$$
T_{c}=\frac{1}{2} M \dot{x}^{2}
$$

Kinetic energy of the system:

$$
T=T_{c}+T_{p}=\frac{1}{2}(M+m) \dot{x}^{2}+m l \dot{x} \dot{\theta} \cos (\theta)+\frac{1}{2} m l^{2} \dot{\theta}^{2}
$$

Potential energy of the system:

$$
U=m g l \cos (\theta)
$$

Energy of the inverted pendulum system:

$$
L=U+T=\frac{1}{2}(M+m) \dot{x}^{2}+m l \dot{x} \dot{\theta} \cos (\theta)+\frac{1}{2} m l^{2} \dot{\theta}^{2}+m g l \cos (\theta)
$$

Euler-Lagrange equation:

$$
\begin{aligned}
& \frac{d}{d t}\left(\frac{\partial L}{\partial \dot{x}}\right)-\frac{\partial L}{\partial x}=F-k \dot{x} \\
& \frac{d}{d t}\left(\frac{\partial L}{\partial \dot{\theta}}\right)-\frac{\partial L}{\partial \theta}=0
\end{aligned}
$$

Replace at (6) by (5) we have :

$$
\left\{\begin{array}{l}
(M+m) \ddot{x}-m l \cdot \sin \theta \cdot \dot{\theta}^{2}+m l \cdot \cos \theta \cdot \ddot{\theta}=F-k \dot{x} \\
m l^{2} \ddot{\theta}+m g l \sin \theta=-m l \ddot{x} \cos \theta
\end{array}\right.
$$

The state equation the inverted pendulum system with $x_{1}=x ; x_{2}=\dot{x}, x_{3}=\theta ; x_{4}=\dot{\theta} ;$ : 


$$
\left\{\begin{array}{l}
\dot{x}_{1}=x_{2} \\
\dot{x}_{2}=\frac{m l \sin x_{3} x_{4}^{2}-m g \cos x_{3} \sin x_{3}+F-k x_{2}}{M+m-m\left(\cos x_{3}\right)^{2}} \\
\dot{x}_{3}=x_{4} \\
\dot{x}_{4}=\frac{m l \sin x_{3} \cos x_{3} x_{4}^{2}-(M+m) g \sin x_{3}+F \cos x_{3}-k x_{2} \cos x_{3}}{m l\left(\cos x_{3}\right)^{2}-(M+m) l}
\end{array}\right.
$$

Suppose that friction and moment of inertia are ignored. Linearize (8) to get balance point $x_{1}=0 ; x_{2}=0 ; x_{3}=0 ; x_{4}=0$; we have the linearized state equation below:

$$
\left[\begin{array}{c}
\dot{x}_{1} \\
\dot{x}_{2} \\
\dot{x}_{3} \\
\dot{x}_{4}
\end{array}\right]=\left[\begin{array}{cccc}
0 & 1 & 0 & 0 \\
0 & 0 & -\frac{m}{M} g & 0 \\
0 & 0 & 0 & 1 \\
0 & 0 & \frac{M+m}{M l} g & 0
\end{array}\right]\left[\begin{array}{c}
x_{1} \\
x_{2} \\
x_{3} \\
x_{4}
\end{array}\right]+\left[\begin{array}{c}
0 \\
\frac{1}{M} \\
0 \\
-\frac{1}{M l}
\end{array}\right] F
$$

Where: $x$ - displacement $(m) ; \dot{x}$ - velocity $(\mathrm{m} / \mathrm{s}) ; \ddot{x}$ - acceleration $\left(\mathrm{m} / \mathrm{s}^{2}\right) ; \theta$ - angular displacement $(\mathrm{rad}) ; \dot{\theta}$ - angular velocity $(\mathrm{rad} / \mathrm{s}) ; \ddot{\theta}$ - angular acceleration $\left(\mathrm{rad} / \mathrm{s}^{2}\right) ; F$ - force $(\mathrm{N}) ; k$ - friction coefficient $(\mathrm{Nm} / \mathrm{A}) ; g$ - gravity acceleration $\left(\mathrm{m} / \mathrm{s}^{2}\right) ; M$ - the chassis volume $(\mathrm{kg}) ; \mathrm{l}$ - length of the pendulum $(\mathrm{m}) ; M$ - Cart mass $(\mathrm{kg}) ; \mathrm{m}$ - Pendulum mass $(\mathrm{kg})$.

\section{Using the quasi-time optimization approach for stabilizing and trajectory tracking}

The nearly optimal method by quick acts has been applied in some studies $[11,26]$. This method has many advantages such as fast duration effect, asymptotic stability, and high stability. In the paper [11], development of control rules on embedded systems with the one - free - step object is shown. Using a nonlinear model for the two - free - step inverted pendulum systems is slightly complicated. Therefore, the authors use the linear system (9) for embedded systems.

Changing state variables as follows:

$$
y_{1}=x_{1}+l x_{3} ; y_{2}=x_{2}+l x_{4} ; y_{3}=x_{3} ; y_{4}=x_{2} ;
$$

It is easy to verify that Jacobian matrix of transformation (3) is not degraded:

$$
\operatorname{det}\left[\frac{\partial y}{\partial X}\right]=\left|\begin{array}{llll}
1 & 0 & l & 0 \\
0 & 1 & 0 & l \\
0 & 0 & 1 & 0 \\
0 & 1 & 0 & 0
\end{array}\right|=-l \neq 0
$$

Where: $X=\left(\begin{array}{llll}x_{1} & x_{2} & x_{3} & x_{4}\end{array}\right)^{T}$.

Equations by $Y=\left(\begin{array}{llll}y_{1} & y_{2} & y_{3} & y_{4}\end{array}\right)^{T}$ :

$$
\left[\begin{array}{l}
\dot{y}_{1} \\
\dot{y}_{2} \\
\dot{y}_{3} \\
\dot{y}_{4}
\end{array}\right]=\left[\begin{array}{cccc}
0 & 1 & 0 & 0 \\
0 & 0 & g & 0 \\
0 & \frac{1}{l} & 0 & -\frac{1}{l} \\
0 & 0 & -\frac{m}{M} g & 0
\end{array}\right]\left[\begin{array}{l}
y_{1} \\
y_{2} \\
y_{3} \\
y_{4}
\end{array}\right]+\left[\begin{array}{c}
0 \\
0 \\
0 \\
1 \\
M
\end{array}\right] F
$$


Equations (12) is in a controllable Jordan form [9]. Virtual system (12), which has asymptotic stablily and quasi - time optimum, is used to synthesize the control law $\mathrm{F}$ with $z_{1}$ $=y_{l} ; u$ is found to introduce the system (12) into the virtual system (13) [9]. The obtained control law is a differentiable function of state variables, of which the formula is very long and therefore not given here.

$$
\left\{\begin{array}{l}
\dot{z}_{1}=-v \frac{z_{1}-x_{s p}}{\sqrt{\left(z_{1}-x_{s p}\right)^{2}+\varepsilon_{1}^{2}}}+z_{2} \\
\dot{z}_{2}=-\frac{z_{2}}{\varepsilon_{2}}+z_{3} \\
\dot{z}_{3}=-\frac{z_{3}}{\varepsilon_{3}}+z_{4} \\
\dot{z}_{4}=-\frac{z_{4}}{\varepsilon_{4}}
\end{array}\right.
$$

Where $h_{0}\left(z, x_{s p}\right)$ is quasi - time optimal function $\left(h_{0}\left(z, x_{s p}\right) \approx \operatorname{sign}\left(z-x_{s p}\right)\right)[8]$.

In researches $[11,23,24]$ the coefficient $v$ is defined as a reactive speed, the value is specified through testing. In this paper, authors determine $v$ to ensure the system in asymptotic stability. From the virtual equation system(13) Lyapunov function can be created as below:

$$
V=\frac{1}{2}\left(z_{1}^{2}+z_{2}^{2}+z_{3}^{2}+z_{4}^{2}\right)
$$

Determined $v$ parameter for $\dot{V}$ to get being negative, we have:

$$
v \geq \sqrt{\left(z_{1}-x_{s p}\right)^{2}+\varepsilon_{1}^{2}} \frac{\varepsilon_{2}\left(4-\varepsilon_{3} \varepsilon_{4}\right)}{4\left(4-\varepsilon_{2} \varepsilon_{3}-\varepsilon_{3} \varepsilon_{4}\right)}
$$

The selected parameters for the simulation model are as following : $\mathrm{M}=0.8(\mathrm{~kg}), \mathrm{m}=0.4$ $(\mathrm{kg}), 1=0.4(\mathrm{~m}), \mathrm{g}=9.81\left(\mathrm{~m} / \mathrm{s}^{2}\right), \mathrm{k}=1, v=1.7, \varepsilon_{1}=0.35, \varepsilon_{2}=\varepsilon_{3}=\varepsilon_{4}=0.2, \mathrm{x}_{\mathrm{sp}}=0.2, \mathrm{x}(0)=0$ $(\mathrm{m}), \dot{\mathrm{x}}(0)=0(\mathrm{~m} / \mathrm{s}), \theta(0)=0(\mathrm{rad}), \theta^{\prime}(0)=0(\mathrm{rad} / \mathrm{s})$.

Fig. 2a, 2b shows the angular response and position of the fast-acting optimal controller and the LQR method when the model meet the friction. Looking at the results, we can conclude that the controller combinated by the above method has the position response which is not overwhelmed compared to the LQR controller, the faster time for the angular response and position, and higher stability.

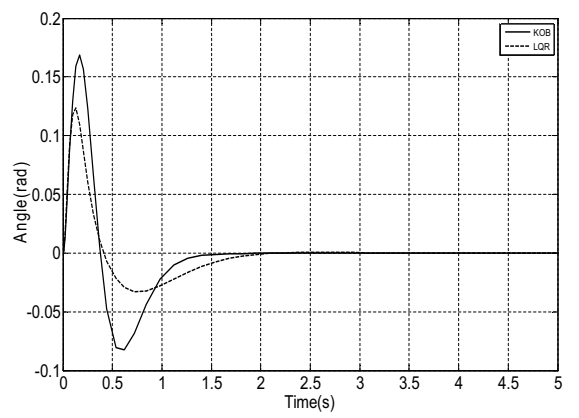

a)

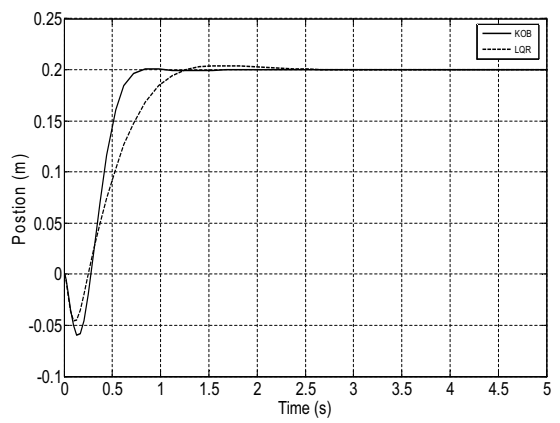

b)

Fig. 2. Simulate how to response the position and balance of the inverted pendulum: a- The angular response of the pendulum; b-The position response. 
Fig. 3 displays the force applied to the vehicle to stabilize the system, it shows that the force determined by the quasi-time optimization approach is smaller than that one determined by the control system LQR. This is very significant in reality for designing embedded systems because of limited resources and energy affect applied to systems.

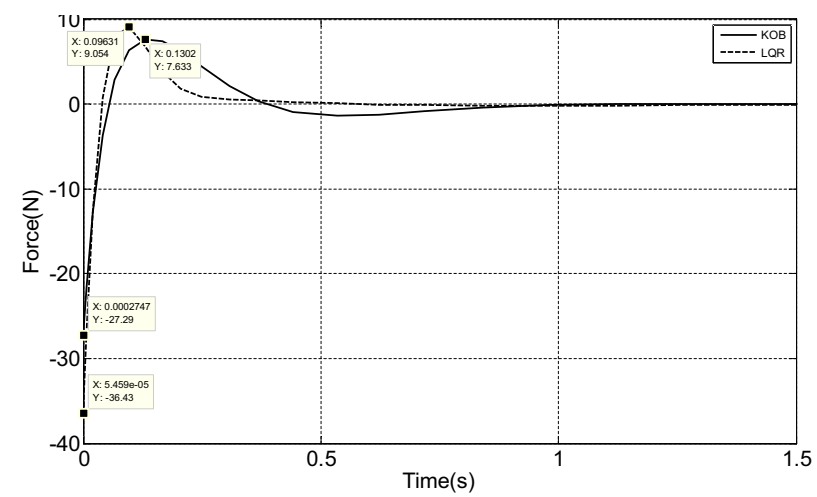

Fig. 3. Force values in $L Q R$ and KOB.

\section{Results are performed on the real-time system}

The control rule is run on the real-time embedded system on the model performed by authors (Figure 4a) with the following parameters: Length of journey $0.7(\mathrm{~m})$; Other parameters like as the simulation part. The vehicle is powered by a DC motor and transmission system - drive belt.

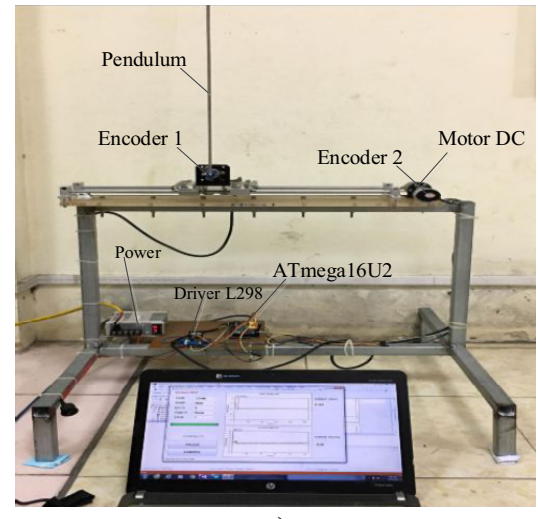

a)

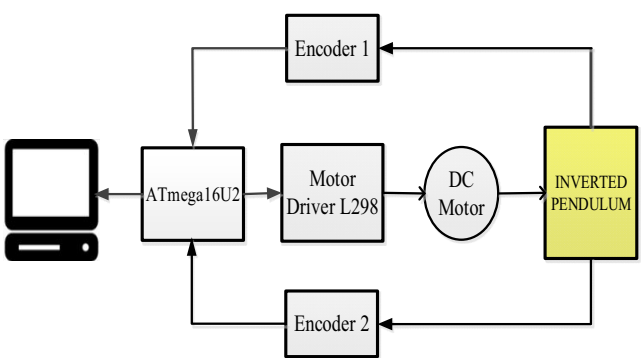

b)

Fig. 4. The inverted pendulum model: a) experimental model; b) diagram of control circuit block.

Diagram of the circuit controlled system is shown in Figure 4b. The ATmega16U2 microcontroller is used as a central processor working at frequency $16 \mathrm{kHz}$. Two angular and position encoders are connected to the microcontroller with 600 pulses / loop. The DC motor is controlled via the controller and the power circuit L298. The system is supplied by a $24 \mathrm{~V} \mathrm{DC}$ power, electric current 2.1 (A). The system are connected to software that collects data via serial port RS232. The software is developed by authors with Visual Studio $\mathrm{C}++$ to observe angle and position values by displaying the numerical and graphical data on the screen (Fig. 5). 


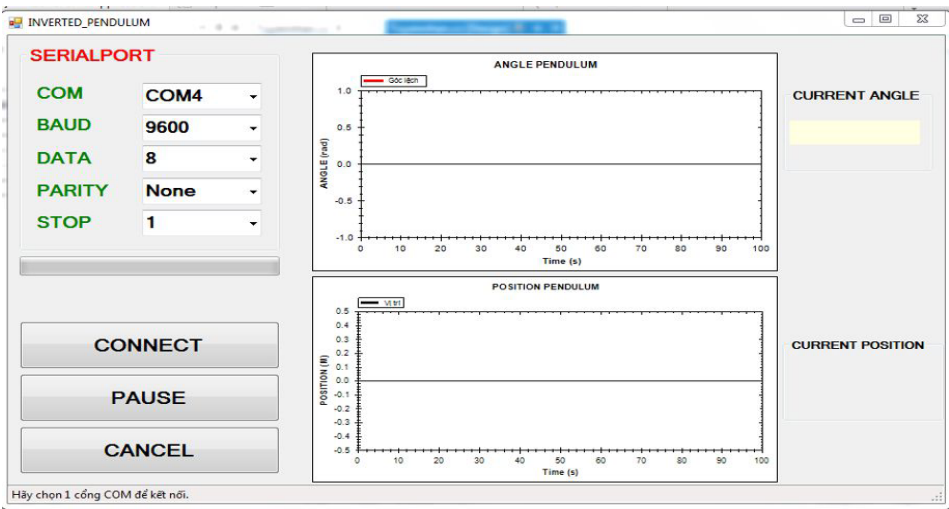

Fig 5. The program interface displays the data.

In Figures 6a, 6b show the responsive angle and position of the inverted pendulum by the fast-acting optimal controller. From the response we can see that the optimal controller has worked with the designed pendulum model. The pendulum is always in equilibrium and only oscillates slightly around the equilibrium position. The position of the pendulum oscillating around the set point tends to fade. We also observe that responsive angle and position which somewhere oscillates with the high frequency is due to mechanical deviation, measurement deviation by using relative encoder. Another reason is that the control rule is not optimal with the real model because of the $\mathrm{v}$ selection, and the epsilon in simulation is approximate.

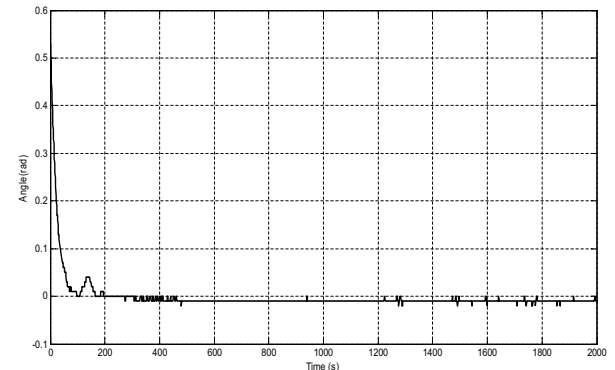

a)

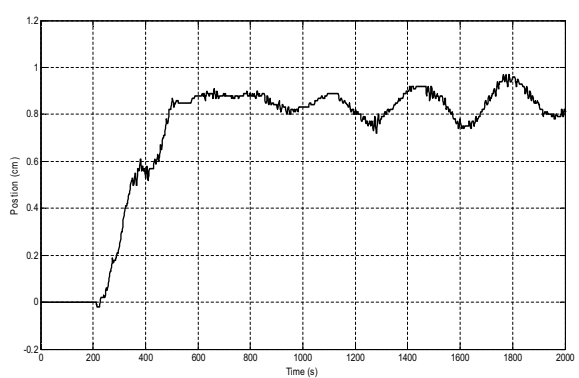

b)

Fig. 6. Satisfaction of the equilibrium angle and position of the real-time system: a- The angular response of the pendulum; b-The position response.

\section{Conclusions}

The paper presents the method of designing the balance control rule of the inverted pendulum system by the fast acting nearly optimal method. The correctness of this control rule has been proven by simulations compared with the LQR controller. The control rule demonstrates its superiority over LQR controllers in terms of response times, stability and energy consumption. Application on the real-time system is done by the authors on the real model. Experimental results also show that although there is oscillation, the fast-acting optimal control rule has stabilized the pendulum and the position at the set point

\section{References}

1. L.B. Prasad, B. Tyagi, H.O. Gupta, International Journal of Automation and Computing, 11(6), 661 (2014) 
2. S. Irfan, A. Mehmood, M.T. Razzaq, J. Iqbal, JESTECH, 21(4), 753 (2018)

3. R. Bitirgen, M. Hancer, I. Bayezit, IFAC-PapersOnLine, 51(4), 346 (2018)

4. L.B. Prasad, B. Tyagi, H.O. Gupta, International Journal of Automation and Computing, 11(6), 661 (2014)

5. S.C. Lin, C.C. Tsai, H.C. Huang, Proceedings of the 2009 IEEE International Conference on Systems, Man, and Cybernetics, 1965 (2009) doi: 10.1109/ICSMC.2009.5346583

6. K.E. Vinodh, J. Jovitha, Procedia Eng., 64, 169 (2013)

7. R. Mellah, F. Lahouazi, S. Djennoune, S. Guermah, R. Toumi, IJCAS, 1 (3) (2012)

8. S.C. Lin, C.C. Tsai, W.L. Luo, In proc. 33rd Annu. IEEE IECON, 868 (2007)

9. H. Ohara, T. Murakami, IEEE Trans. Ind. Electron, 55, 1277 (2008)

10. K.E. Vinodh, J. Jovitha, IConDM 2013 Procedia Eng., 64, 169 (2013)

11. Hai N. Phan, Chiem X. Nguyen, MATEC Web Conf. 132, 02005 (2017)

12. M.A. Khanesar, M. Teshnehlab, M.A. Shoorehdeli, Control \& Automation, MED'07. Mediterranean Conference on. IEEE, 1, (2007)

13. A. Jain, D. Tayal, N. Sehgal, International Journal of Computer Applications, 69(27), 0975 (2013)

14. S.S. Sonone, N.V. Patel, International Journal of Science and Research, 4, 1172 (2013)

15. L. B. Prasad, B. Tyagi, H. O. Gupta, In Proceedings of IEEE International Conference on Control System, Computing and Engineering, 540 (2011) doi: 10.1109/ICCSCE.2011.6190585

16. Y. M. Liu, Z. Chen, D. Y. Xue, X. H. Xu, In Proceedings of IEEE International Conference on Automation and Logistics, $1180 \quad$ (2009) doi: 10.1109/ICAL.2009.5262618

17. X. Gong, Z. C. Hu, C. J. Zhao, Y. Bai, Y. T. Tian, International Journal of Automation and Computing, 9(5), 555 (2012)

18. S. Radhamohan, A. Subramaniam, D. Nigam, Journal of Theoretical and Applied Information Technology, 14(1/2), 43 (2010)

19. F.-K. Tsai, J.-S. Lin, 4th International Conference on Control and Automation. Final Program and Book of Abstracts(ICCA), 634 (2003) doi:10.1109/ICCA.2003.1595099

20. X. Chen, H. Zhou, R. Ma, F. Zuo,G. Zhai, M. Gong, Proceedings of the IEEE International Conference on Automation and Logistics, 1750 (2007) doi: 10.1109/ICAL.2007.4338856

21. D. Chatterjee, A. Patra, K. Joglekar, System \& Control Letters, 47(4), 355 (2002)

22. R.A. Neydorf, Vestnik DSTU, 13 (1999)

23. N. H. Phan, Metody raspoznavaniya upravlyayemykh zhordanovykh form dinamicheskikh sistem $i$ ikh dekompozitsii na zhordanovy podsistemy $v$ zadachakh sinteza kvazioptimal'nykh po bystrodeystviyu zakonov upravleniya, Diss. kand. tekhn. nauk. 05.13.01 (Rostov-na-Donu, 2008)

24. M.N. Mohsen, R.A. Neydorf, E-journal Engineering journal of Don, 38, 4-1 (2015)

25. R. Neydorf, SAE Technical Paper, 2015-01-2481 (2015) doi: 10.4271.2015-01-2481

26. R. Neydorf, Y. Sigida, V. Voloshin, Y. Chen, SAE Technical Paper, 2013-01-2111, (2013) doi:10.4271/2013-01-2111

27. B. S. Park, S.J. Yoo, J.B. Park, and Y.H. Choi, IEEE Trans. Control Syst. Technol., 17 (1), 207 (2009) 